\title{
Effects of geolocators on reproductive performance and annual return rates of a migratory songbird
}

Jesús Gómez ${ }^{1,2,3,7}$, Chantel I. Michelson ${ }^{1,2}$, David W. Bradley ${ }^{4,5}$, D. Ryan

Norris $^{5}$, Lisha L. Berzins ${ }^{6}$, Russell D. Dawson ${ }^{6}$, Robert G. Clark ${ }^{1,2}$

${ }^{1}$ Prairie and Northern Wildlife Research Centre, Environment Canada, Saskatoon, Saskatchewan S7N 0X4, Canada

${ }^{2}$ Department of Biology, University of Saskatchewan, Saskatoon, Saskatchewan S7N 5E2,

Canada

${ }^{3}$ Doñana Biological Station, EBD-CSIC, Americo Vespucio Rd. 41092, Seville, Spain

${ }^{4}$ Bird Studies Canada, Port Rowan, Ontario NOE 1MO Canada

${ }^{5}$ Department of Integrative Biology, University of Guelph, Guelph, Ontario N1G 2W1

Canada

${ }^{6}$ Ecosystem Science and Management, University of Northern British Columbia, 3333

University Way, Prince George BC V2N $4 Z 9$ Canada

${ }^{7}$ Corresponding author: j.gomez@ebd.csic.es 
1 Abstract Our understanding of the annual life-cycle movements of small migratory birds has

2 advanced rapidly with the advent of light-weight geographical positioning devices (i.e.,

3

4

5

6

7 geolocators), yet the effects of geolocators on reproduction and survival have not been adequately quantified. We tested for impacts of attaching a $1 \mathrm{~g}$ geolocator (using a harness around the legs and back, anterior to the tail) to adult Tree Swallows (Tachycineta bicolor) on parental feeding behaviour, nestling growth and size, fledging success, and return rates between 2011-2012. At one breeding site, we compared feeding visits, nestling growth, and nestling size between paired nest boxes where one parent was marked at the 'geolocator' box with a 'control' nest box where neither parent was marked. We detected no differences between geolocator and control nests in either the frequency of feeding visits to nestlings or the amount of time spent at nests. Birds marked with geolocators fed nestlings as frequently as their unmarked mates. Likewise, nestlings raised at geolocator nests grew at similar rates to those at control nests, and had similar structural size and body mass at fledging. At three widely-separated sites across the Tree Swallow breeding range in Canada, we also found that fledging success was similar for geolocator and control nests. Although we found no evidence for short-term negative impacts of geolocators, the return rates of geolocatormarked swallows tended to be significantly lower than those of unmarked control birds. Thus, we found little evidence for short-term impacts of geolocators on reproduction but our study does suggest that long-term impacts of geolocators could be manifested in terms of lower survival, higher emigration rates, or lower breeding propensity.

Key words feeding rate $\cdot$ fledging success $\cdot$ migration $\cdot$ nestling growth $\cdot$ Tachycineta bicolor $\cdot$ Tree Swallow 


\section{Introduction}

Tracking the movements of migratory birds between their breeding and non-breeding grounds is critical for understanding life-history trade-offs (Jahn et al. 2010; Boyle et al. 2011), factors that influence fitness and population abundance (Webster et al. 2002; Norris et al. 2004), and for developing effective conservation and management plans (Martin et al. 2007; Klaassen et al. 2008; Sheehy et al. 2010). Despite the importance of understanding migration pathways, tracking small migratory birds has been extremely challenging because banded individuals are rarely recaptured (Reichlin et al. 2009; Korner-Nievergelt et al. 2012), satellite transmitters are too heavy for most species (Bridge et al. 2011), and intrinsic markers, such as stable isotopes (Hobson and Wassenaar 2008), have limited resolution and are unable to provide data on migration routes. However, recent advances in the use of lightlogging geolocators have now allowed researchers to track the migration routes of birds weighing as little as few decagrams (e.g., Rodríguez et al. 2009a; Stutchbury et al. 2009; Bächler et al. 2010; Egevang et al. 2010; Åkesson et al 2012; Bairlein et al. 2012; Stach et al. 2012; Stanley et al. 2012). Geolocators use integrated measurements of ambient light and time to provide daily estimates of latitude and longitude (Hill 1994). Although this technology provides unique information on long-distance movements (Heckscher et al. 2011), there has yet to be a formal evaluation of the potential impacts of geolocators on small, free-ranging songbirds. Barron et al.’s (2010) review of avian transmitter effects reported negative impacts on many aspects of behaviour and ecology, and geolocators have been shown to influence body mass and breeding success in raptors and seabirds, respectively (Rodríguez et al. 2009b, Elliot et al. 2012).

Geolocators are often attached to songbirds in the same way as similar-sized radio transmitters: a harness attached to the device loops around the legs so the geolocator rests on the back of the individual between the wings (Rappole and Tipton 1991; Stutchbury et al. 
2009). Although most previous research on radio transmitters has found little evidence for negative effects on foraging or survival (Rae et al. 2009; Gow et al. 2011; Townsend et al. 2012), this may not be similar for geolocators. For instance, some radio transmitter attachments are designed to fall off after several weeks or months, so overall impacts could be reduced. In a wind tunnel experiment, the geolocator's light-sensing stalk, which usually protrudes 2-6 mm from the main devices, increases drag (Bowlin et al. 2010) which could interfere with normal activities and flight, aerobic performance, or result in lower survival rates. Lower survival or site fidelity rates are of particular concern because one major drawback of using geolocators is that individuals must be recaptured at some later point in time, typically the following year, to retrieve location data. Thus, there is the possibility that geolocators may provide biased information on migratory movements if a non-random sample of individuals is recaptured.

Here, we examine the effects of geolocators on the reproductive performance and return rates in adult Tree Swallows (Tachycineta bicolor), a small ( 20g) migratory aerial insectivore that breeds in temperate areas of North America and winters in the southeastern United States, the Caribbean, Mexico and Central America (Winkler et al. 2011). We examined the hypothesis that geolocators compromise the success of adults by lowering current reproductive performance and reducing the probability of returning to breed the following season. At one breeding site, we compared nestling feeding rates, nestling size and nestling growth rates at geolocator nest boxes where one adult was marked with a geolocator to boxes attended by unmarked control birds. At the same site, and two additional breeding sites spanning the breeding range of Tree Swallows in Canada, we compared breeding success and return rates of adults with and without geolocators.

\section{Methods}


Study Areas

Field work was conducted during 2011-2012 at three widely-separated Tree swallow breeding sites in Canada: Saskatchewan [SK], Ontario [ON], British Columbia [BC]. The 385 ha St. Denis National Wildlife Area (NWA; 52 $12^{\prime} \mathrm{N}, 106^{\circ} 04^{\prime} \mathrm{W}$ ) is located $40 \mathrm{~km}$ east of Saskatoon, SK. The NWA consists of small groves of trees, mainly aspen (Populus tremuloides), separated by areas of cropland, native and planted grasslands, shrubs, and wetlands (Shutler and Clark 2003). In ON, data were collected near Long Point (42³9’ N, $\left.80^{\circ} 26^{\prime} \mathrm{W}\right)$, an area consisting of hayfields, sand dunes, lake shorelines and a disused sewage lagoon (Hussell 2003). The BC site was near Prince George (5350’ N, 12257’ W) and characterized by hayfields interspersed among areas of mature and regenerating forest (Dawson 2008). For all three sites, we present data related to fledging success and adult return rates. At the SK site only, we analyzed the influence of geolocators on parental feeding behaviour and nestling sizes and growth rates.

\section{Nest monitoring}

Tree Swallows readily use nest boxes because natural nest cavities may be limited (Shutler and Clark 2003). Nest boxes and general monitoring protocols are described by Shutler and Clark (2003) and Shutler et al. (2006). Briefly, nest boxes were placed 1.5 m above ground on metal t-bars or fence posts and spaced approximately $30 \mathrm{~m}$ apart. From early May to July, nests were visited daily or every other day to monitor timing of breeding (i.e., first egg dates), clutch size, and hatching and fledging success.

We captured adults within a few days of when the last egg hatched in each clutch, banded (except recaptured birds), weighed (nearest $0.25 \mathrm{~g}$ with a Pesola scale [SK, BC], 0.1g with a digital balance [ON]), and we recorded unflattened wing chord and 9th primary (nearest 1 $\mathrm{mm}$ with a wing ruler) lengths, and head-bill (nearest $0.05 \mathrm{~mm}$ with calipers) length (Pyle et 
al. 1987). Adults were sexed by presence or absence of a brood patch (only females incubate) or cloacal protuberance (Pyle et al. 1987; Winkler et al. 2011). Birds at geolocator nests were recaptured when their nestlings were $>7$ days old (mean age $=10 \pm 3.3$ days SD), weighed again, and geolocators were attached. At the SK site, we used measurements recorded at the first capture to compare body mass and wing length of males and females in the control and geolocator groups. In SK, nestling measurements were taken at 12 and $16 \mathrm{~d}$ post-hatching using methods described above for adults (except head-bill length because of low repeatability), enabling us to determine growth between 12 and 16 days of age.

Geolocators and attachment method

All adults equipped with geolocators had been previously banded at the same study site, had active nests in the year geolocators were attached, and weighed $>19.5 \mathrm{~g}$. These individuals were equipped with a $0.67 \mathrm{~g}$ light-sensing geolocator (Lotek Wireless model MK12-S in 2011, MK5-S in 2012), attached using a backpack harness (Stutchbury et al. 2009; $0.96 \mathrm{~g}$ with harness, $<5 \%$ of body weight). Attachment involved a figure-eight harness that loops around the legs and over the back. The geolocator sat just in front of the tail, and did not directly impede movement of the wings. Harnesses were fabricated from $1 \mathrm{~mm}$ diameter ethylenepropylene-diene rubber O-rings (O-Rings West Inc., Seattle, WA), which were cut into different lengths to ensure a proper fit. The resulting exposed harness loop lengths varied between 38 - $40 \mathrm{~mm}$. During attachment we placed a small amount of cyanoacrylate adhesive (Krazy Glue ${ }^{\circledR}$, Columbus, $\mathrm{OH}$ ) between the geolocator and the contour feather on the bird's back, with additional feathers arranged to cover the geolocator and reduce drag. Different adult swallows were marked with geolocators in 2011 and 2012. 
In 2011 and 2012 at the SK site, we monitored parental feeding rates as they provisioned 16day old nestlings. Two observers monitored all nests, alternating between control and geolocator nests (where one parent had a geolocator). Number of visits and time spent (nearest sec) at the nest box were recorded. Observations began at randomly selected times between 0900 and 1500 hours and lasted 40 min (see Bortolotti et al. 2011 for rationale). We tried to reduce disturbance by arriving $5-10$ min before the start time and observing nests using a spotting scope or binoculars from a sitting position $>50 \mathrm{~m}$ from nests. An average of 5 days (range $=2-9$ days) elapsed between the date that geolocators were attached to birds and the nest observation period. In 2012, we marked one adult with a geolocator and the other member of the pair was temporarily marked on the outermost tail feathers with nontoxic typewriter correction fluid, enabling us to determine which bird(s) fed nestlings.

\section{Fledging success}

In both years at all sites, the number of nestlings was recorded for each brood at hatch, and nests were visited again 20-21 days post-hatch after young had fledged. The percent of young that fledged successfully from each nest was estimated as number of young that fledged divided by the number hatched.

Return rates

At all sites, adults that had been recaptured (i.e., band-only or geolocator-marked adults) in 2011 were classified as recaptured or not in 2012. Banded adults with no geolocators that had raised nestlings during the same span of nesting dates as geolocator-marked birds were included in the control group. Return rates should not be interpreted as representing true survival rates because swallows marked with geolocators could have lower breeding propensity or higher emigration rate. 
Statistical analyses

All analyses were performed in SAS (SAS Institute 2003). Body mass, head-bill and wing length measurements of male and female swallows in the control and geolocator nests were compared with generalized linear models (Proc GLM), with fixed effects of sex and marking group, an interaction between sex and marking group, and controlling possible effects of measurement date. When possible, at all three sites we matched nests by hatch date ( \pm 1 day) and number of nestlings ( \pm 1 nestling) where one adult had been marked with a geolocator with control nests attended by unmarked adults. At SK, number of visits and time spent (cube root transformed to improve normality for analyses only) at nest boxes in each group were compared using paired $t$-tests in 2011; in 2012, there were data for five pairs of geolocator and control boxes, and Wilcoxon signed ranks tests were used for all comparisons (Siegel and Castellan 1988). Comparisons of nestling size and growth in 2011 were analyzed with mixed effects models to account for clustering of nestlings within families, i.e., nest box as the random effect, and marking group, brood size and measurement date as fixed effects (Proc Mixed). For all three sites, we used Wilcoxon tests to compare percent fledging success between boxes attended by geolocator-marked and unmarked birds, and return rates were compared using $G$-tests and logistic regression. Unless indicated otherwise, we present least squares means (LSM) and 95\% confidence intervals (95\% CI).

\section{Results}

After controlling for effects of measurement date at the SK site, neither body mass nor morphological measurements of adult males and females differed between control and geolocator groups (all $P s>0.39$ ), nor was there an interaction between sex and marking 
group (all Ps $>0.13$ ). Therefore, parents in these groups had similar characteristics when captured immediately post-hatch ( $\mathrm{n}=88$ adults).

Feeding observations, and nestling size and growth

At SK in 2011, no differences were detected between geolocator and control nests in terms of number of feeding visits (paired $t_{22}=0.61, P=0.55$ ) or time spent at nest boxes (paired $t_{22}=$ $0.32, P=0.75$ ) by adult swallows (Fig. 1); parents in the control and geolocator-marked nests visited nests with similar frequency during the 40 min observation period (controls: LSM = $17,95 \% \mathrm{CI}=14-19$ visits; geolocators: $\mathrm{LSM}=18,95 \% \mathrm{CI}=15-21$ visits $)$ and, overall, parents were at nests for about 5 min (controls: LSM = 295 sec, 95\% CI = 195-395 sec; geolocators: LSM = 313 sec, 95\% CI = 213-413 sec).

In 2012 at SK, there were similar numbers of total visits made to nests attended by control $($ median $=21$ visits, range $=17-41)$ and geolocator $($ median $=30$ visits, range $=23-40)$ adults, and the amount of time (control: median $=324 \mathrm{sec}$, range $=131-615 \mathrm{sec}$; geolocator: median $=221$ sec, range $=117-348$ sec) spent in nest boxes did not differ (Wilcoxon signed ranks tests, $P=0.19$ and $P>0.50, \mathrm{n}=5$ pairs of nests). Likewise, at five geolocator nest boxes where one parent was marked with white correction fluid, geolocator-marked birds visited nests (median $=10$ visits, range $=9-24$ ) as frequently as their mates marked temporarily with correction fluid (median $=13$ visits, range $=2-17$ ) and the amount of time spent at nests (geolocator: median $=86 \mathrm{sec}$, range $=53-112$ sec; white: median $=97 \mathrm{sec}$, range $=5-165 \mathrm{sec}$ ) was also similar (Wilcoxon signed ranks tests, both $P \mathrm{~s}>0.50$ ).

Body size measurements and growth rates of nestlings were similar in each marking group in 2011 at SK (Table 1), after controlling for nest box effects $(P s<0.001)$ in mixed model analyses. Size of 16-day-old nestlings was unrelated to whether or not a parent was marked with a geolocator ( $P s>0.44)$, and there was similarly no effect detected of geolocators on 
growth between day 12 and 16 ( $P$ s $>0.10)$. There was no interaction between brood size and marking group in any of these analyses (all Ps $>0.25$ ). Brood sizes did not differ between marking groups ( $G$-test, $\left.G_{3}=0.53, P=0.91\right)$.

\section{Fledging success}

At the SK site, fledging success was 100\% in 2011 for broods in geolocator and control nests ( $n=23$ pairs of nests). Likewise, fledging success was 100\% at another 17 nests where an adult was marked with a geolocator (brood size at 12 days post-hatching ranged from 1-8 nestlings) but a matched control nest was not available. In 2012, fledging success was 93.8\% and $88.3 \%$ for geolocator and control nests ( $\mathrm{n}=22$ pairs of nests), respectively, with fledging success ranging from $0-100 \%$ in both groups and brood sizes ranging from 3-9 nestlings; no difference was detected between marking groups (Wilcoxon test, $P>0.50$ ).

At the ON site in 2011, mean fledging success was 90.5\% (range $=50-100 \%$ ) for 25 nests with a geolocator-marked adult and 71.7\% (range $=0-100 \%$ ) for 25 control nests (Wilcoxon test, $P>0.50$ ). In 2012, mean fledging success was $98.1 \%$ (range $=83.3-100 \%$ for both groups; Wilcoxon test, $P>0.50)$ in geolocator and control boxes (n $=9$ pairs of nests).

At the BC site, we found no differences between marking groups in either year (Wilcoxon tests, $P$ s $>0.40$ ). In 2011, mean fledging success rates were $66.9 \%$ (range $=0-100 \%$ ) and $70.2 \%$ (range $=0-100 \%$ ) at 11 pairs of nests attended by geolocator and control birds, respectively; corresponding estimates for 9 pairs of nests were $91.1 \%$ for geolocator nests (range $=40-100 \%$ ) and 97.2\% for control nests (range $=75-100 \%)$ in 2012. There were no appropriate matched controls for five nests where one member of the pair had a geolocator, with three occurring in 2011 (fledging success: 0\%, 100\%, 100\%) and two in 2012 (60\%, $80 \%)$. 
Return rates

Overall, return rates differed among sites $\left(G_{2}=10.50, P=0.005\right)$, being higher in ON $(50.0 \%, n=110)$, intermediate $(45.5 \%, n=143)$ in SK and lower in BC (31.6\%, $n=152)$. In SK, 30\% of 40 geolocator-marked adults were recaptured in 2012 (Fig. 2), but one male had shed its geolocator. At SK, return rates were lower for adults marked with geolocators (logistic regression: $\beta=-0.425 \pm 0.202 \mathrm{SE}, P=0.04$ ) when compared with controls, and for females $(\beta=-0.384 \pm 0.171 \mathrm{SE}, P=0.03)$ when compared with male birds, but there was no evidence for a marking type*sex interaction $(P=0.27)$. In $\mathrm{ON}$, return rates were similar for geolocator (48\%) and control groups (51\%; logistic regression, $P=0.40)$ and between sexes ( $P=0.68)$; no marking group by sex interaction effect $(P=0.83)$ was found (Fig. 2). Only 7.5\% of birds equipped with geolocators in BC returned in 2012 (although one returning male had shed the geolocator), a rate that was significantly lower than control birds, of which 40.2\% returned (Fig 2; logistic regression, $\beta=-1.052 \pm 0.313, P<0.001$ ). At $\mathrm{BC}$, there was no difference between sexes $(\beta=0.083 \pm 0.184, P=0.65)$ and no marking group by sex interaction $(P=0.63)$.

\section{Discussion}

Adverse effects of externally-mounted markers are frequently reported (see Barron et al. 2010), but we found no evidence that placing geolocators on Tree Swallows produced any detectable short-term effects on feeding behavior, nestling growth and size, or breeding success. Likewise, Schmaljohann et al. (2012: supplementary material) detected no adverse effects of attaching geolocators to male Northern Wheatears (Oenanthe oenanthe) on either subsequent breeding performance or return rates (Schmaljohann et al 2012). Because, in 2011, we only marked one adult at each nest, it is possible that unmarked birds compensated for reduced effort by their geolocator-marked mates, so that overall provisioning rates in each 
marking group appeared similar (Fig. 1). Although we cannot completely rule out this possibility, we observed marked birds feeding at 20 of 23 nests at Saskatchewan, sometimes frequently, so we believe that this explanation is unlikely. Furthermore, in 2012, when both sexes were marked at a subsample of nests at Saskatchewan, geolocator-marked birds fed nestlings just as often as their white color-marked mates. Finally, we did not detect an interaction between marking group and brood size in any analyses of Saskatchewan data, although previous results from mate-removal experiments (or due to natural mate loss) indicate that individual Tree Swallows are able to compensate for loss of a mate in small or average-sized broods (Leffelaar and Robertson 1986; Quinney 1986), which suggests that impacts of geolocators might be most evident in larger broods.

If marked birds had delivered smaller amounts or lower quality food at each visit, this change in provisioning was not manifested in reduced nestling growth rates or size at fledging at Saskatchewan (Table 1). Given that swallows experienced favorable weather and foraging conditions during our study at Saskatchewan, it is possible that swallows were able to adjust easily to any possible adverse effects imposed by the geolocators. Short-term effects of geolocators may be more evident during challenging conditions of inclement weather and food scarcity (Murray and Fuller 2000; Igual et al. 2005; Rodríguez et al. 2009b).

The combined mass of geolocator and harness was $<5 \%$ of an adult swallow's body mass, near the recommended upper limits for devices placed on birds and several other vertebrates (Kenward 2001). However, some studies report extended foraging trip duration and reduced breeding success in birds carrying transmitters that represent only 3\% of body mass (Phillips et al. 2003). If longer foraging trips occurred in our study, presumably the number of visits would have been lower in the geolocator group but this effect was not found. The addition of a 1g geolocator was within the range of body mass changes observed at Saskatchewan from the first captures of adults (when the last egg had hatched) to the second capture when 
geolocators were attached (overall, mean $=-0.9 \mathrm{~g}, \mathrm{SD}=1.3, \mathrm{n}=40$ ); an average of 10 days elapsed between these two capture events, so perhaps swallows are capable of short-term adjustments to higher wing loading. Finally, the attachment method we employed was designed to reduce handling time, ensure that the harness did not impede wing movement (Bowlin et al. 2010), and was explicitly tailored to fit both smaller and larger swallows. Presumably, all of these factors had the potential to reduce short-term adverse impacts on birds. Furthermore, peak nestling food demands likely occurred before we marked adults with geolocators (Zach and Mayoh 1982; McCarty 2001), so impacts on feeding behaviour may be found by marking adults with geolocators when nestlings are younger.

Our study was designed to control for effects of observer bias, brood size, nestling age and daily changes in food supply. We also verified, albeit in a post-hoc manner, that morphological characteristics of marked and unmarked adults did not differ at Saskatchewan. Therefore, preferential marking of heavier swallows did not result overall in a nonrepresentative sample in terms of the variables we measured. However, the latest-nesting birds at our sites, possibly those of lower quality, were not marked but may be more susceptible to deleterious effects of geolocators.

Overall, we obtained no consistent evidence of adverse effects of geolocators on fledging success at any site. In 2011 at Saskatchewan, fledging success was 100\% at all nests in our study, including at 17 geolocator nests that lacked adequate controls, and indices of nestling quality were unrelated to marking group (Table 1). In 2012, fledging success exceeded 88\%, with no difference between marked and control pairs. Parent birds marked with geolocators continued to feed nestlings, suggesting that short-term marking effects were insufficient to provoke abandonment in either year. Fledging success varied annually at Ontario and particularly at British Columbia, but was unrelated to marking group. This result could signal that local breeding success was more closely related to prevailing environmental conditions 
such as weather and food supply. Indeed, the low return rates of swallows at British Columbia in 2012 could be related to effects of carrying geolocators during adverse conditions experienced by adults in 2011 (i.e., when they fledged fewer nestlings).

The result of greatest concern for the application of geolocators was the low return rate of adults marked with geolocators at the British Columbia and Saskatchewan sites (Fig. 2).

Overall, sex-specific impacts were equivocal; only females at Saskatchewan had lower return rates than males, possibly due to their smaller size (Winkler et al. 2011) or relatively higher investment in reproduction. At the Ontario site, point estimates of return rates of geolocatorequipped swallows were only slightly lower than controls in both sex cohorts. Given that study sites were $>1,000 \mathrm{~km}$ apart, return rates may reflect spatiotemporal differences in overwinter and spring environmental conditions that mediate individuals' responses to the impacts of geolocators (Tøttrup et al. 2012). Anecdotal observations from British Columbia (LLB) suggest that 1-4 birds equipped with geolocators had returned to the study site, but were not recaptured; similar observations were not made at Ontario or Saskatchewan. Stutchbury et al. (2009) reported that 54\% of banded Purple Martins (Progne subis) were recaptured at breeding colonies, but only $10 \%$ were recaptured after marking with geolocators. Combined with findings reported here, this suggests that survival rates, dispersal behavior or breeding propensity could be adversely affected by these devices, at least in some species of aerial insectivores. Thus, longer-term study of songbirds and other species is needed to distinguish among these explanations, as well as determine whether individuals marked with geolocators provide reliable information about timing, duration and direction of migratory movements.

Acknowledgements We are grateful to A.J. Green, J.A. Amat, V.B. Harriman, K.W. Dufour, H. Schmaljohann and two anonymous reviewers for constructive comments on the 
manuscript. Thanks to V.B. Harriman C. McKay, D. LeClair, A. Lenske, A. McKintosh, J. Mirabelli, E. Ospina, L. Schmader, C. Soos and G. Treen for help with fieldwork. JG was supported by an Argo GLOBAL grant, promoted by the Spanish Ministry of Education, Culture and Sports and managed by the FICYT. Funding was provided by the Canadian Foundation for Innovation (DRN), Natural Sciences and Engineering Research Council of Canada (NSERC) Discovery Grants (DRN, RDD, RGC), an NSERC IRDF Fellowship (DWB), an NSERC Canada Graduate Scholarship (LLB), Bird Studies Canada (DWB, DRN), and Environment Canada (RGC). Bird manipulations complied with the current laws of Canada, and animal use regulations at the University of Saskatchewan (20070041), the University of Northern British Columbia (ACUC-2011-13), and the University of Guelph (11R042). 


\section{References}

Åkesson S, Klaassen R, Holmgren J, Fox JW, Hedenström A (2012) Migration routes and strategies in a highly aerial migrant, the Common Swift Apus apus, revealed by lightlevel geolocators. PLoS ONE 7(7):e41195.

Bächler E, Hahn S, Schaub M, Alrettaz R, Jenni L, Fox JW, Afanasyev V, Liechti F (2010) Year-round tracking of small trans-Saharan migrants using light-level geolocators. PLoS ONE 5(3):e95566.

Bairlein F, Norris DR, Nagel R, Bulte M, Voigt CC, Fox JW, Hussell DJT, Schmaljohann H (2012) Cross-hemisphere migration of a 25 g songbird. Biol Lett 8:505-507.

Barron DG, Brawn JD, Weatherhead PJ (2010) Meta-analysis of transmitter effects on avian behaviour and ecology. Methods Ecol Evol 1:180-187.

Bortolotti LE, Harriman VB, Clark RG, Dawson RD (2011) Can changes in provisioning by parent birds account for seasonally declining patterns of offspring recruitment? Can J Zool 89:921-928.

Bowlin MS, Henningsson P, Muijres FT, Vleugels RHE, Liechti F, Hedenström A (2010) The effects of geolocator drag and weight on the flight ranges of small migrants. Methods Ecol Evol 1:398-402.

Boyle WA, Guglielmo CG, Hobson KA, Norris DR (2011) Lekking birds in a tropical forest forego sex for migration. Biol Lett 7:661-663.

Bridge ES, Thorup K, Bowlin MS, Chilson PB, Diehl RH, Flerón RW, Hartl P, Kays R, Kelly JF, Robinson WD, Wikelski M (2011) Technology on the move: recent and forthcoming innovations for tracking migratory birds. BioSci 61:689-698.

Dawson RD (2008) Timing of breeding and environmental factors as determinants of reproductive performance of tree swallows. Can J Zool 86:843-850. 
Egevang C, Stenhouse IJ, Phillips RA, Petersen A, Fox JW, Silk JRD (2010) Tracking of Arctic Terns Sterna paradisaea reveals longest animal migration. Proc Natl Acad Sci USA 107:2078-2081.

Elliott KH, McFarlane-Tranquilla L, Burke CM, Hedd A, Montevecchi WA, Anderson VG (2012) Year-long deployments of small geolocators increase corticosterone levels in murres. Mar Ecol Prog Ser 466:1-7.

Gow EA, Done TW, Stutchbury BJM (2011) Radio-tags have no behavioral or physiological effects on a migratory songbird during breeding and molt. J Field Ornithol 82: 193201.

Heckscher CM, Taylor SM, Fox JW, Afanasyev V (2011) Veery (Catharus fuscescens) wintering locations, migratory connectivity, and a revision of its winter range using geolocator technology. Auk 128:531-542.

Hill RD (1994) Theory of geolocation by light levels. In: Burney J, Le Boeuf BJ Laws RM (eds) Elephant Seals: Population Ecology, Behaviour, and Physiology. University of California Press, Berkeley, CA, pp 227-236.

Hobson KA and Wassenaar L (2008) Tracking animal migration with stable isotopes. Academic Press, London, UK, 160 pp.

Hussell DH (2003) Climate change, spring temperatures, and timing of breeding of tree swallows (Tachycineta bicolor) in southern Ontario. Auk 120:607-618.

Igual JM, Forero MG, Tavecchia G, González-Solis J, Martínez-Abraín A, Hobson KA, Ruiz X, Oro D (2005) Short-term effects of data-loggers on Cory's Shearwater (Calonectris diomedea). Mar Biol 146:619-624.

Jahn AE, Levey DJ, Hostetler JA, Mamani AM (2010) Determinants of partial bird migration in the Amazon Basin. J Anim Ecol 79:983-992. 
Kenward RE (2001) A manual for wildlife radiotagging. Academic Press, London, UK. 311 pp.

Klaassen M, Bauer S, Madsen J, Possingham H (2008) Optimal management of a goose flyway: migrant management at minimum cost. J Applied Ecol 45:1446-1452.

Korner-Nievergelt F, Liechti F, Hahn S (2012) Migratory connectivity derived from sparse ring reencounter data with unknown numbers of ringed birds. J Ornithol 153:771-782.

Leffelaar D, Robertson RJ (1986) Equality of feeding roles and the maintenance of monogamy in Tree Swallows. Behav Ecol Sociobiol 18:199-206.

Martin TG, Chadès I, Arcese P, Marra PP, Possingham HP, Norris DR (2007) Optimal Conservation of Migratory Species. PLoS ONE 2(8):e751.

McCarty JP (2001) Variation in growth of nestling Tree Swallows across multiple temporal and spatial scales. Auk 118:176-190.

Murray DL, Fuller MR (2000) A critical review of the effects of marking on the biology of vertebrates. In: Boitani L, Fuller TK (eds) Research techniques in animal ecology controversies and consequences. Columbia University Press, New York, pp 15-64.

Norris DR, Marra PP, Kyser TK, Sherry TW, Ratcliffe LM (2004) Tropical winter habitat limits reproductive success on the temperate breeding grounds in a migratory bird. Proc R Soc B 271:59-64.

Phillips RA, Xavier JC, Croxall JP (2003) Effects of satellite transmitters on albatrosses and petrels. Auk 120:1082-1090.

Pyle P, Howell SNG, Yunick RP, DeSante DF (1987) Identification Guide to North American Passerines. Slate Creek Press, Bolinas, USA, 278 pp.

Quinney TE (1986) Male and female parental care in Tree Swallows. Wilson Bull 98:147150. 
Rae LF, Mitchell GW, Mauck RA, Guglielmo CG, Norris DR (2009) Radio transmitters do not affect the body condition of Savannah Sparrows during the fall premigratory period. J Field Ornithol 80:419-426.

Rappole JH, Tipton AR (1991) New harness design for attachment of radio transmitters to small passerines. J Field Ornithol 62:335-337.

Reichlin TS, Schaub M, Menz MHM, Mermod M, Portner P, Arlettaz R, Jenni L (2009) Migration patterns of Hoopoe Upupa epops and Wryneck Jynx torquilla: an analysis of European ring recoveries. J Ornithol 150:393-400.

Rodríguez A, Negro, JJ, Bustamante J, Fox JW, Afanasyev V (2009a) Geolocators map the wintering grounds of threatened Lesser Kestrels in Africa. Diversity Distrib 15:1010 1016.

Rodríguez A, Negro JJ, Fox JW, Afanasyev V (2009b) Effects of geolocator attachments on breeding parameters of Lesser Kestrels. J Field Ornithol 80:399-407.

Schmaljohann H, Buchmann M, Fox JW, Bairlein F (2012) Tracking migration routes and the annual cycle of a trans-Sahara songbird migrant. Behav Ecol Sociobiol 66:915-922

Sheehy J, Taylor CM, McCann KS, Norris DR (2010) Optimal conservation of migratory animals: integrating demographic information across seasons. Conservation Letters 3: 192-202.

Shutler D, Clark RG (2003) Causes and consequences of Tree Swallow (Tachycineta bicolor) dispersal in Saskatchewan. Auk 120:619-631.

Shutler D, Clark RG, Fehr C, Diamond AW (2006) Time and recruitment costs as currencies in manipulation studies on the costs of reproduction. Ecology 87:2938-2946.

Siegel S, Castellan NJ (1988) Nonparametric Statistics for the Behavioral Sciences. Second edition. McGraw-Hill, Inc., New York. 399 pp. 
Stach R, Jakobson S, Kullberg C, Fransson T (2012) Geolocators reveal three consecutive wintering areas in the Thrush Nightingale. Animal Migration. doi:10.2478/ami-20120001.

Stanley CQ, MacPherson M, Fraser KC, McKinnon EA, Stutchbury BJM (2012) Repeat Tracking of Individual Songbirds Reveals Consistent Migration Timing but Flexibility in Route. PLoS ONE 7(7): e40688. doi:10.1371/journal.pone.0040688.

SAS Institute (2003) SAS/STAT user’s guide. Version 9.1. SAS Institute, Cary, North Carolina, USA.

Stutchbury BJM, Tarof SA, Done T, Gow E, Kramer PM, Tautin J, Fox JW, Afanasyev V (2009) Tracking long-distance songbird migration by using geolocators. Science 323:896-896.

Tøttrup AP, Klaassen RHG, Kristensen MW, Strandberg R, Vardanis Y, Lindström Å, Rahbek C, Alerstam T, Thorup K (2012) Drought in Africa caused delayed arrival of European songbirds. Science 338: 1307.

Townsend JM, Rimmer CC, McFarland KP (2012) Radio-transmitters do not affect seasonal mass change or annual survival of wintering Bicknell's Thrushes. J Field Ornithol 83:295-301.

Webster MS, Marra PP, Haig SM, Bensch S, Holmes RT (2002) Links between worlds: unraveling migratory connectivity. Trends Ecol Evol 17:76-83.

Wikelski M, Yays RW, Kasdin NJ, Thorup K, Smith JA, Swenson GW (2007) Going wild: what a global small-animal tracking system could do for experimental biologists. J Exp Biol 210:181-186.

Winkler DW, Hallinger K, Ardia DR, Robertson RJ, Stutchbury BJ, Cohen RR (2011) Tree Swallow (Tachycineta bicolor). In: A. Poole (ed) The Birds of North America Online Ithaca: Cornell Lab of Ornithology. 
Zach R, Mayoh KR (1982) Weight and feather growth of nestling Tree Swallows. Can J Zool 60:1080-1090. 
Table 1. Body size measurements at 16 days post-hatching and growth of body components from day 12 to day 16 for nestling Tree Swallows raised in nest boxes by unmarked parents (control) or at nests where one parent was marked with a geolocator, St. Denis,

Saskatchewan, Canada, in 2011. Shown are sample size of nestlings (n), mean, and lower and upper 95\% confidence intervals of wing length (mm), 9 th primary length (mm) and body mass (g). There were 23 nest boxes in each group, matched for hatching date and brood size. Growth refers to the difference (i.e., day 16 minus day 12) in body size measurements.

\begin{tabular}{|c|c|c|c|c|c|c|c|c|}
\hline & \multicolumn{4}{|c|}{ Control } & \multicolumn{4}{|c|}{ Geolocator } \\
\hline & $\mathrm{n}$ & Mean & Lower & Upper & $\mathrm{n}$ & Mean & Lower & Upper \\
\hline \multicolumn{9}{|l|}{ Body size (day 16): } \\
\hline Wing length & 147 & 74.8 & 73.9 & 75.7 & 147 & 75.4 & 74.7 & 76.1 \\
\hline $9^{\text {th }}$ primary length & 147 & 49.1 & 48.2 & 50.0 & 147 & 49.4 & 48.7 & 50.1 \\
\hline Body mass & 147 & 22.8 & 22.5 & 23.1 & 147 & 22.6 & 22.4 & 22.9 \\
\hline \multicolumn{9}{|c|}{ Growth (day 12 to 16 ): } \\
\hline Wing length & 147 & 21.1 & 20.5 & 21.6 & 147 & 20.0 & 19.4 & 20.5 \\
\hline $9^{\text {th }}$ primary length & 116 & 21.6 & 20.9 & 22.2 & 133 & 21.4 & 21.0 & 21.8 \\
\hline Body mass & 146 & -0.9 & -1.1 & -0.6 & 147 & -0.8 & -1.0 & -0.6 \\
\hline
\end{tabular}




\section{Figure Legends}

Fig. 1. Number of visits (in a 40 min observation period) to feed nestlings made by adult Tree Swallows marked with geolocators (one parent marked) versus unmarked controls in relation to brood size, St. Denis, Saskatchewan, Canada, 2011. Data points are slightly offset from exact brood sizes, but a few points remain hidden; $n=23$ pairs of nests matched for hatch date and brood size.

Fig. 2. Return rates $(\% ; \pm 1 \mathrm{SE})$ of male and female adult Tree Swallows marked with standard leg bands (filled bars) or geolocators (open bars) at study sites in British Columbia, Saskatchewan and Ontario, Canada, 2011-2012. Sample sizes (control, geolocator) shown in parentheses. 
Fig. 1

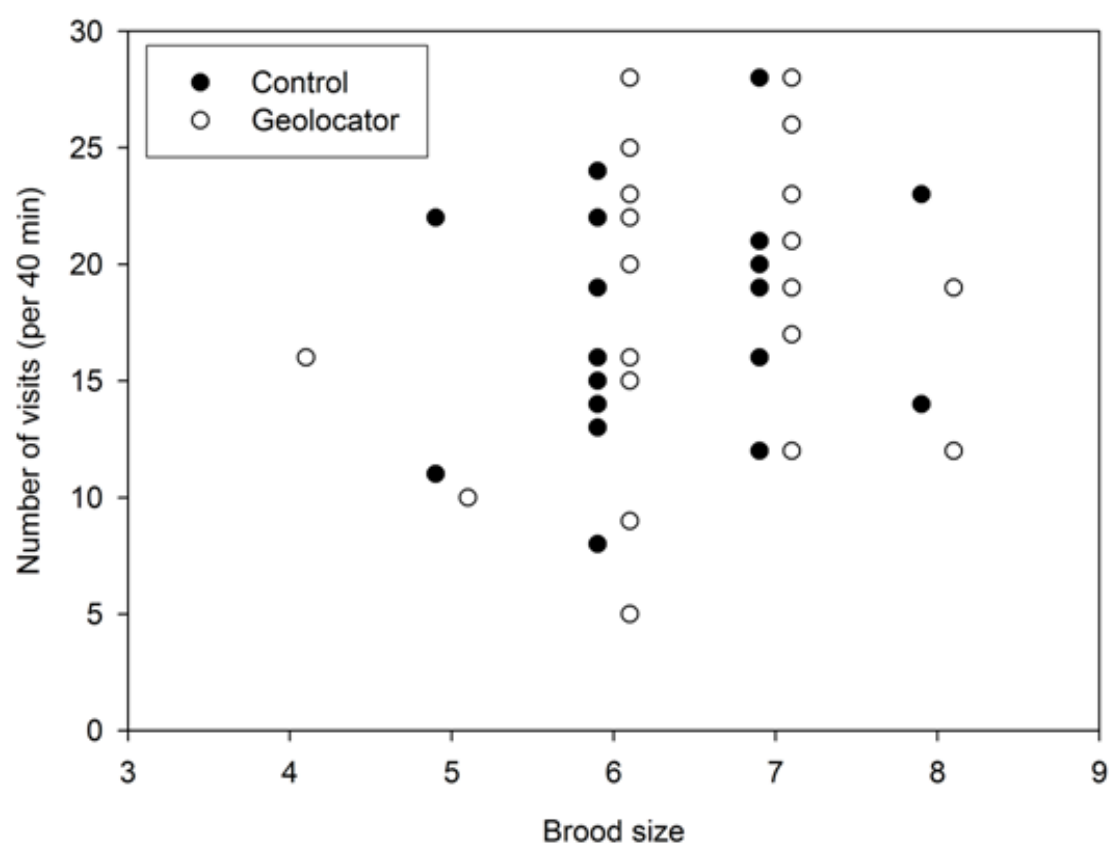


Fig. 2

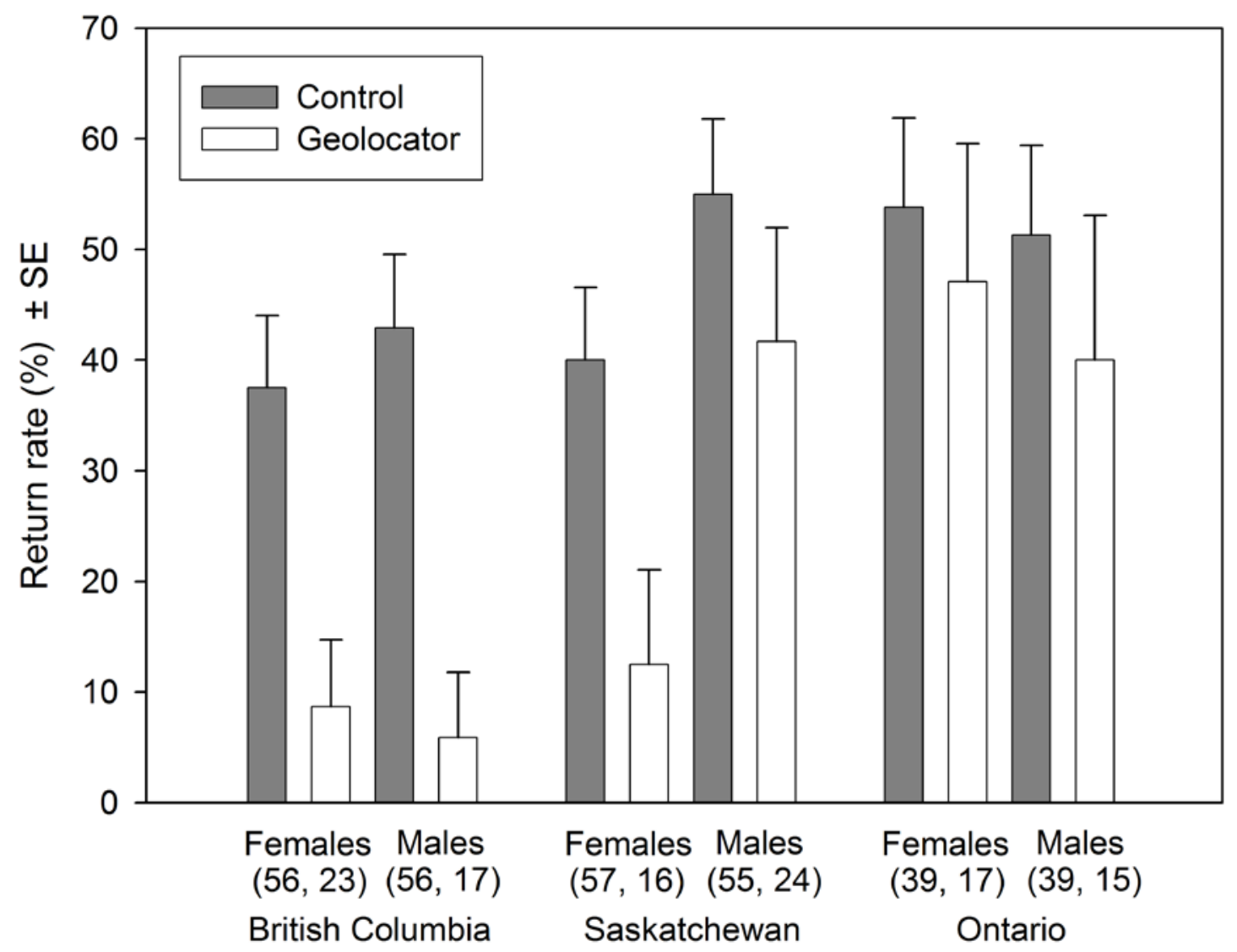

